\title{
DIFFERENTIAL EFFECTS OF INTERNAL AND EXTERNAL CONSTRAINTS ON SUSTAINABILITY INTENTIONS A HIERARCHICAL REGRESSION ANALYSIS OF RUNNING EVENT PARTICIPANTS BY MARKET SEGMENT
}

GALEN TRAIL

(corresponding author)

Albers School of Business and Economics

Seattle University

Seattle, Washington, U.S.A.

trailg@seattleu.edu

BRIAN P. MCCULLOUGH

Albers School of Business and Economics

Seattle University

Seattle, Washington, U.S.A.

mccullob@seattleu.edu

ABSTRACT. There are immediate calls to action across all business sectors to address the adverse effects of climate change. The sport industry is not immune to these calls - practitioners have engaged participants to further the environmental initiatives of their events through creative messaging campaigns with mixed success. We examine the differential effects of internal and external constraints on sustainability intentions by market

CITATION OF THIS ARTICLE IN PRESS: Trail, G., \& McCullough, B. P. 2018. Differential Effects of Internal and External Constraints on Sustainability Intentions: A Hierarchical Regression Analysis of Running Event Participants by Market Segment. Journal of Management for Global Sustainability 6(2). 
segment of a running event's participants. This furthers our understanding of how to engage sport participants in sustainable behaviors at a sport event and improves the sustainable behavior outcomes of messaging campaigns. Our results support the principles of constraint theory and that internal constraints need to be addressed before external constraints are relevant. Internal constraints, such as lack of knowledge and lack of worth, predict variance in intentions to act sustainably (i.e., to dispose of waste correctly). After controlling for internal constraints, the external constraints of lack of interest by others to act sustainably, and lack of access and time, explain additional variance in sustainability intentions. We also found that each market segment varies on the impact of constraints that inhibit sustainability intentions, with the amount of variance in sustainability intention explained by such constraints varying from as low as $11.4 \%$ in one segment to as high as $33.1 \%$ in another. We then provide specific recommendations for future research and discuss how practitioners can use these results to ameliorate these constraints and increase sustainability intentions.

KEYWORDS: sustainability; constraints; market segmentation

There is an increased number of calls for immediate action to combat and greatly reduce the causes of climate change (Kates et al., 2001; United Nations, 2016: 1-27). Indeed, dealing with the impending effects of climate change requires a collective effort, from large corporations to individuals, to alleviate adverse environmental impacts. This shared responsibility is a major component of the current environmental movement to achieve sustainability goals (Sartore-Baldwin, McCullough, $\&$ Quatman-Yates, 2017). Large corporations, for instance, have responded with commitments to lessen their adverse impact on the environment through various sustainability initiatives (e.g., reduce landfill waste [Babiak \& Trendafilova, 2011; Ihlen, 2009]). However, while such efforts are laudable, these large organizations do not seem to be in a position to engage their customers or stakeholders directly and in an effective way to further their environmental sustainability efforts (Ashforth \& Gibbs, 1990; Morsing \& Schultz, 2006).

The United Nations Climate Change Secretariat sees sport as a possible touchpoint for engaging individuals about climate change and for promoting more sustainable behaviors at events and in people's everyday lives (United Nations, 2017). That is, sport, in general, presents a unique context because of its universal appeal, and specifically because of the affinity individuals have with sport brands when compared to other business sectors (Fink, Trail, \& Anderson, 2002; Sutton, McDonald, Milne, \& Cimperman, 1997). The environmental sustainability efforts in the sport sector have been characterized by waves of commitment; 
indeed, sport organizations have reduced their environmental impact by modifying business operations within their control (e.g., procurement, resource management, etc.). Yet, because of the dynamics of the sport industry (i.e., a service industry) and due to their considerable contribution to the overall environmental impact of an event (e.g., production of waste; Babiak \& Trendafilova, 2011; Collins, Jones, \& Munday, 2009; Trendafilova, McCullough, Pfahl, Nguyen, Casper, \& Picariello, 2014), it is necessary to engage sport participants as part of the next wave of environmental sustainability in the sport sector (McCullough, Pfahl, \& Nguyen, 2016).

Sport organizations have the opportunity to encourage their participants to behave more sustainably and see why it is necessary to do so (Sartore-Baldwin \& McCullough, 2018). There are, however, many constraints or barriers that individuals must overcome to engage in sustainable behaviors, including, among others, a lack of basic awareness of opportunities for such behaviors, feelings that sustainable behaviors are not worthwhile, a lack of support from others, and a lack of time and accessibility in a sport event context (McCullough, 2013; McCullough \& Cunningham, 2011). These categories of constraints are likely present for individuals outside of sport (cf. Kaplowitz, Yeboah, Thorp, \& Wilson, 2009), for sport spectators (cf. McCullough, 2013), and for sport participants (like in this study). However, the degree that these categories impact behavior or behavioral intentions may differ due to the context. The task of encouraging sustainable behavior in sport participants becomes challenging in specific contexts in which sustainable behaviors have never been requested, and thus the success of these efforts are very reliant on sound managerial practices to remove any external barriers (United Nations, 2010). Therefore, further examination is needed to bolster such efforts given that sport event managers who launch engagement campaigns to promote sustainable behavior changes among participants have met with mixed success (McCullough et al., 2016).

There also remain marketing objectives that need to be resolved to maximize the event's sustainable legacy (O'Brien \& Chalip, 2007) and encourage sustainable behavior change among participants (e.g., runners in a race). Thus, while previous researchers have examined the value-action gap between environmental values and sustainable behaviors (e.g., Juvan \& Dolnicar, 2014), it is necessary for advancing the sustainable legacy of an event to examine whether this gap can be bridged and whether perceptions of barriers differ among specific active sport participant segments. The ability to bridge this gap will allow sport managers to organize and communicate sustainability initiatives more effectively to consumers and increase levels of sustainable behaviors. Different sport or leisure contexts (e.g., spectating, fishing, 
hiking, running, etc.), however, may bring different specific behavioral constraints within a category (e.g., lack of knowledge) due to their specific situation. Examination of sports participants, therefore, is necessary for determining the behavioral constraints they encounter while engaging in their active participation.

To this end, the purpose of this study is to examine the barriers that prevent sustainable behaviors and how to overcome such among runners in a 10-mile race (The Run). This study adds to the growing body of knowledge to enhance current sustainability efforts of the sport and leisure sectors to increase the innovation for sustainability of current industry practice by identifying specific behavioral constraints that inhibit sustainable behaviors. By examining this context and leveraging the social platform of sport, sustainable behaviors can be influenced at the event and eventually in everyday lives (Casper, Pfahl, \& McCullough, 2017).

\section{THEORETICAL BACKGROUND}

Understanding the influences and impediments of attitudes and behaviors is important for identifying and overcoming them to promote positive sustainability intentions and subsequent behavioral change. Most importantly, it is necessary to identify the constraints that inhibit an individual from engaging in the desired behavior. Thus, while constraints have been defined differently in other academic disciplines, we use Trail and James's (2015) definition of constraints as the factors (or reasons) that prevent or prohibit an individual from participating in some activity.

Lepisto and Hannaford (1980) identified five types of constraints to purchasing products. Cultural constraints are related to cultural values and norms that lead to decreased purchasing whereas social constraints are defined more narrowly as the negative influences of reference groups. Marketing constraints represent a lack of fit between the product and the consumer from an organizational perspective. Structural constraints reduce consumption because of temporal, spatial, or physical challenges. Personal constraints are related to the lifestyle of the consumer. Nevertheless, while Lepisto and Hannaford's constraints are focused more on purchasing and consumption behavior rather than on participation behavior, most of the defined constraints are probably applicable in the case of this study.

Crawford and Godbey (1987) built upon Iso-Ahola's (1981) research on barriers to leisure participation but neither they nor Iso-Ahola 
mentioned research from the business realm; both come more from a counseling perspective. According to their theoretical model, Crawford and Godbey suggested that constraints among participants of leisure activities could be divided into three main categories: intrapersonal, interpersonal, and structural. Intrapersonal constraints were seen as making up an individual's psychological state that could inhibit their motivation for engaging in a specific leisure behavior. Interpersonal constraints influence an individual through social connections or networks that may impede the individual's preference and participation in a specific behavior. Structural constraints were conceptualized as physical or contextual aspects that could deter a specific leisure behavior. Each individual, however, does not experience equally the influence of each category of constraints. Thus, it is necessary to understand the varying degrees of influence these constraints have in inhibiting the desired behavior.

Crawford, Jackson, and Godbey (1991) proposed a hierarchical model of leisure constraints to address and explain the conceptual links between the constraint constructs. They argued that constraints were determined by a hierarchy of importance and concluded that an individual would not be able to participate in a leisure activity until after these constraints had been overcome in sequential order. It was a clarified model considerably criticized by other researchers (Kay \& Jackson, 1991; Scott, 1991; Shaw, Bonen, \& McCabe, 1991). There has been limited support for Crawford and colleagues' three dimensions because the intrapersonal and interpersonal constraints at times lacked discriminant validity while intrapersonal and structural constraints overlapped in some instances. Some researchers even reported that behavioral constraints as proposed by Crawford et al. (1991) were not, in fact, constraints to engage in specific behaviors (Kay \& Jackson, 1991; Scott, 1991; Shaw et al., 1991).

To address the concerns with Crawford et al.'s (1991) model, Kim and Trail (2010) proposed a two-dimensional model of constraints, echoing previous arguments about the discriminant validity of the three constraint constructs as proposed by Crawford and Godbey (1987) and the subsequent conceptual model proposed by Crawford et al. (1991). Kim and Trail argued that the intrapersonal and interpersonal should be paired together and conceptualized as internal constraints, which they defined as the "internal psychological cognitions that deter behavior" (Kim \& Trail, 2010: 194). They likewise conceptualized Crawford et al.'s structural constraints as external constraints, defining these as the "social and environmental aspects that prevent or decrease the likelihood of an individual performing the behavior" (p. 194). Indeed, they found that their two-dimensional model of constraints (internal 
and external) worked well and had good construct and discriminant validity. An assessment of Kim and Trail's model vis-à-vis the five categories proposed by Lepisto and Hannaford (1980) shows that the cultural, social, marketing, and structural constraints of the latter's work fit within Kim and Trail's external constraint dimension while their personal constraints are similar to Kim and Trail's internal dimension. In addition, all general categories seem relevant to both participative behavior and purchase behavior as defined by Kim and Trail.

Kim and Trail (2011) showed later on that a hierarchical model of constraints existed, with internal constraints entering the model first followed by external ones, thereby explaining the additional variance. They found that internal constraints (e.g., lack of knowledge, perceived lack of worth) typically needed to be overcome first before external constraints (e.g., lack of interest from others, lack of access/time) could be addressed (Kim \& Trail, 2011); both, however, needed to be ameliorated for sustainability behaviors or behavioral intentions to increase. For example, sport organizations are making greater efforts to engage their participants in sustainability behaviors to promote the organization's sustainability initiatives. To engage participants properly in these environmental sustainability campaigns, however, it is necessary to get them to act in environmentally sustainable ways (e.g., recycling, waste diversion).

Engaging sport participants (e.g., runners) in sustainable behaviors can significantly reduce the environmental impact of the organization or event (Collins et al., 2009; Kellison \& McCullough, 2016). Previous researchers, however, have focused on sport spectators rather than sport participants. These two categories differ in their consumption of a sporting event-passive consumption (i.e., watching) as compared to active consumption (i.e., participating; see McDonald, Milne, \& Hong, 2002 for a further discussion on such differences). Nevertheless, it is our premise that the general categories of constraints still exist regardless of the distinction between active or passive consumption of sport; only the focal point of the action or behavior changes. For example, the potential internal constraint of lack of awareness exists whether the focal action is participating in a sustainability campaign during a $10 \mathrm{~K}$ run or attending a sporting event. In both cases, a lack of awareness will prevent the individual from doing either behavior. As of yet, researchers examining sustainable behaviors in various sport contexts (McCullough, 2013; McCullough \& Cunningham, 2011) have not adequately examined or determined the influence of internal and external constraints on sustainability intentions, especially among sporting participants (e.g., runners in an organized event). 


\section{CONSTRAINTS AND SUSTAINABILITY INTENTIONS}

As with other behaviors, constraints are the main obstacles that must be overcome for one to engage in sustainability efforts. Research has examined sustainability intention constraints in various contexts, such as from home (Martin, Williams, \& Clark, 2006), on campus (Kaplowitz et al., 2009), and at sporting events (McCullough, 2013; McCullough \& Cunningham, 2011). For instance, Kaplowitz et al. found, while evaluating communication strategies, that lack of knowledge of how and what to recycle significantly decreased intentions to do so. In a similar vein, Martin et al. showed that lack of time to recycle and lack of resources provided by the city were also significant constraints that inhibited intentions to recycle while at home.

Previous researchers have also explored ways to evaluate and explain sustainability intentions within a sport context (Casper, Pfahl, \& McCullough, 2014, 2017; Martin, Ross, \& Irwin, 2015; McCullough, 2013; McCullough \& Cunningham, 2011). These attempts examined behavior from multiple theoretical perspectives, including values-beliefs-norms (VBN; Stern, Dietz, Kalof, \& Guagnano, 1995) and theory of planned behavior (TPB; Ajzen, 1991). The latter framework is based on how behavioral constraints influence individuals whether or not to engage in specific behaviors. Using the TPB, McCullough and Cunningham (2011) examined the influence that lack of time, conscientious thought to recycle, and access to recycling receptacles (Taylor \& Todd, 1995) had on perceived recycling behavioral controls while attending a weekendlong tournament. They did not find these constraints to have significant influence on sustainability intentions.

In an extension of the aforementioned work, McCullough (2013) also examined the sustainability intentions of football tailgaters. He found that the internal constraints of lack of knowledge of how to act sustainably and the perceived lack of worth of acting sustainably reduced sustainable behaviors among them. That is, the tailgaters were less likely to act sustainably when they did not know how or what to recycle, and when they did not recognize or understand the value (or worth) of recycling. He also found that external constraints such as the lack of interest from significant others decreased intentions to recycle while tailgating, i.e., individuals who did not have others around them that were interested in acting sustainably (such as recycling) were less likely to act sustainably themselves.

Despite these findings, however, it is still necessary to understand and explain the value-action gap between environmental attitudes and 
sustainability intentions (Juvan \& Dolnicar, 2014). Further examination is needed to identify which constraints are significant and need to be ameliorated-if not eliminated-to successfully promote sustainable behaviors among sport participants. To this end, we propose a hierarchical constraints model in which internal constraints (specifically lack of knowledge and perceived lack of worth) predict sustainability intentions and where external constraints (lack of interest from others and lack of access/time) predict additional variance in sustainability intentions (after controlling for internal constraints [see Figure 1]).

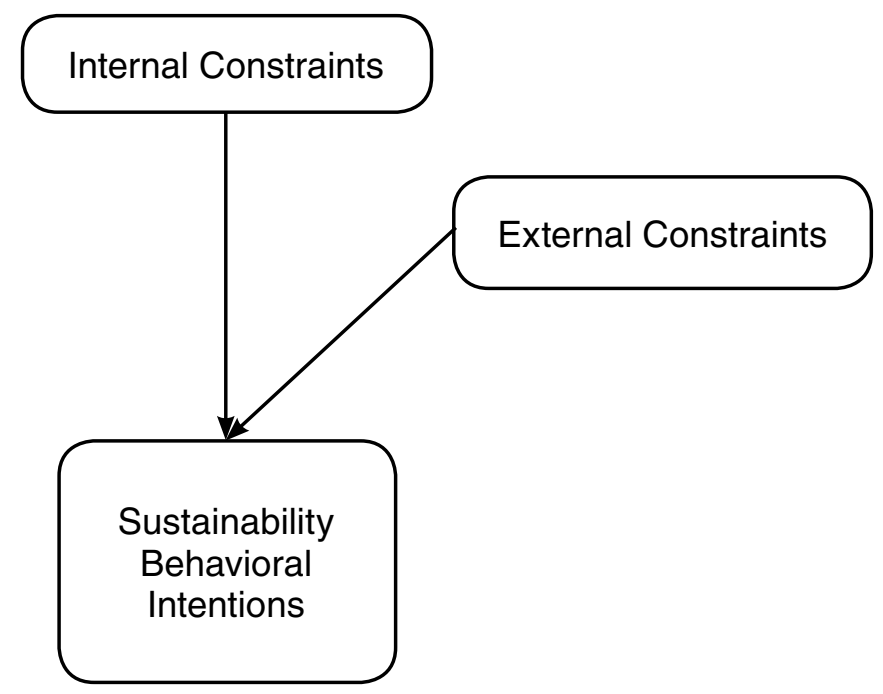

Figure 1: Model of Constraints

Based on this proposed hierarchical constraint model and existing literature, we propose the following hypotheses:

Hypothesis 1: Internal constraints will negatively impact sustainability intentions.

Hypothesis 2: After internal constraints are controlled for, external constraints will explain additional variance in sustainability intentions while further reducing them.

\section{MARKET SEGMENTATION}

While the above hypotheses will allow us to assess whether the model works and whether internal and external constraints will impact 
sustainability intentions for the entirety of the sample, Belz and Peattie (2012) suggested that there are differences among people and how "they perceive and respond to [a] sustainability agenda" (p. 104). Thus, there may be different groups (segments) of participants who perceive the constraints as impacting sustainability intentions to a greater or lesser degree compared to other segments. It is necessary, therefore, to determine whether segments exist and, if so, how they differ within the existing model because determining how to eliminate or ameliorate the constraints will vary across segments, as will the communications necessary to connect with each. As Belz and Peattie noted, it would be unwise, due to contextual factors and situational constraints, to base segmentation decisions on prior or generic research data.

Market segmentation is defined as "the process of dividing the total market for a particular product or product category into relatively homogeneous segments or groups" (Ferrell \& Hartline, 2005: 135). This cannot be done randomly_as Wedel and Kamakura (2000) suggested, there are six criteria for segmentation: identifiability, substantiality, accessibility, stability, responsiveness, and actionability. Identifiability refers to the segment's being recognizable according to some type of distinctive basis such as psychographic, behavioral, or demographic data. A segment is substantial if it is large enough to be worth assessing, accessible if the organization can reach and communicate with it. Stability refers to the idea of the segment as not varying considerably over time and thus requiring marketing or communication adjustments. Responsiveness is concerned with how the segment is "unique enough to respond to differentiated marketing mixes" (Trail \& James, 2015: 99). Finally, actionability has to do with a segment being defined accurately enough so that managers can effectively and efficiently communicate with it in a sufficiently differentiated manner. Meeting these criteria will allow organizations to "[better cope] with the diversity of consumers and their (sustainability) behavior" (Belz \& Peattie, 2012: 153) so that each segment can receive information that is specific and relevant to it.

Belz and Peattie (2012) also suggest that using psychographic variables such as values, attitudes, and needs to determine sustainability market segments is preferable to other methods such as using geographic or demographic variables (although behavioral variables are very useful in some instances). Segments may vary not only by mean scores on referent sustainability attitudes and behaviors but on the relationships among those attitudes and behaviors. These varying relationships require different communication strategies because the impact of certain variables-constraints in our case-may differ across segments (Belz \& Peattie, 2012). 
Based on the above information, we thus propose our next hypothesis:

Hypothesis 3: This model will hold across market segments but the impact of specific constraints on intentions will vary by segment.

\section{METHOD}

\section{Study Context}

We worked with the event organizers of The Run, an annual 10-mile "fun-run" held every spring in the mid-Atlantic region of the United States, to evaluate the effectiveness of their campaign messaging strategy. The Run uses a lottery system to award spots to participants, with 17,000 runners randomly selected out of all those who sign up. Its organizers have expanded their environmental sustainability initiatives in recent years to achieve a higher sustainability certification through the Council for Responsible Sport.

\section{Sample and Procedure}

The Run event organizers emailed a link to our survey questionnaire to approximately 17,000 people in their database. They also posted the link on their Facebook page and website. The initial email was sent two weeks before the race and was followed by two reminder emails about five days apart. The survey was closed on the day before The Run took place. The research project was approved by our Institutional Review Board.

We obtained a 5\% response rate (746 respondents) but had only 531 complete responses for this analysis, which exceeds the required sample size of 376 for a confidence level of $95 \%$ and a margin of error of $5 \%$. Of the participants who sent in completed surveys, 93\% had completed college $(\mathrm{N}=502)$ and most were male $(79.3 \%)$. The average household income was close to six figures $(\$ 98,000)$. While a slight majority $(54.8 \%)$ lived within 15 miles of where The Run took place, the average distance traveled was 85 miles as $10 \%$ of the runners came from more than 250 miles away to participate. There were no significant differences for any of the demographic variables between those that completed the survey before the final reminder and those that completed it on the final day of the survey (approximately 10\% of the respondents), giving some evidence of the sample's representation of the population. 


\section{Instrument}

We used two internal constraint dimensions. The first, Lack of Knowledge, had three items that measured a lack of understanding or knowledge about sustainability, waste diversion, and appropriate disposal of waste. The second, Lack of Worth, had three items that measured a perception that waste diversion, recycling, and acting in an environmentally friendly way were not worthwhile. The former items, from Kim and Trail (2010), were slightly modified to focus on sustainability; the latter three, from Pritchard, Funk, \& Alexandris (2009), were similarly revised.

We also included two external constraint dimensions: Lack of Interest from Others had three items modified from Kim and Trail (2010) that measured a lack of support from friends, significant others, and family in acting sustainably while Lack of Access/Time included four items about the lack of easily accessible waste receptacles, the ease of throwing waste on the ground instead of accessing receptacles, the understanding that race workers will clean up the wrappers thrown on the ground, and the lack of time to look for waste receptacles. These latter items were based on the general concepts from Pritchard et al. (2009).

We also included an item measuring the intention to dispose of waste properly during The Run (sustainability intention) that was created specifically for this research. The specific items in each dimension are listed in their respective figures (Figures 2-6). All items have a 7-point Likert-type response format from 1 "Strongly Disagree" to 7 "Strongly Agree."

\begin{tabular}{|c|l|}
\hline Item Name & \multicolumn{1}{c|}{ Item Definition } \\
\hline \multicolumn{2}{|c|}{ Behavioral Intention } \\
\hline intention & $\begin{array}{l}\text { The next time I participate in the Cherry Blossom } \\
\text { Run I will make sure to dispose of my wrappers/cups } \\
\text { in an appropriate receptacle. }\end{array}$ \\
\hline \multicolumn{1}{|c|}{ Lack of Knowledge } \\
\hline lacknow1 & $\begin{array}{l}\text { I don't understand what the term "sustainable" } \\
\text { means when applied to a race like the Cherry } \\
\text { Blossom Run. }\end{array}$ \\
\hline lacknow4 & I don't understand what the term "waste diversion" means. \\
\hline lacknow5 & $\begin{array}{l}\text { I don't know how to appropriately dispose of my } \\
\text { wrappers while I'm running the race }\end{array}$ \\
\hline
\end{tabular}




\begin{tabular}{|c|l|}
\hline Item Name & \multicolumn{1}{c|}{ Item Definition } \\
\hline lackworth2 & $\begin{array}{l}\text { I don't understand why The Run is worried about } \\
\text { diverting waste from the landfill. }\end{array}$ \\
\hline lackworth3 & I don't think recycling is worthwhile. \\
\hline lackworth4 & $\begin{array}{l}\text { Acting in an environmentally friendly way won't } \\
\text { improve the environment enough to make a difference }\end{array}$ \\
\hline \multicolumn{2}{|c|}{ Lack of Interest from Others } \\
\hline lackint1 & My family is not interested in acting sustainably. \\
\hline lackint2 & My significant other is not interested in acting sustainably. \\
\hline lackint3 & My friends are not interested in acting sustainably. \\
\hline \multicolumn{2}{|c|}{ Lack of Time/Access } \\
\hline lacktime1 & $\begin{array}{l}\text { I don't have time to find a waste receptacle while I'm } \\
\text { running the race. }\end{array}$ \\
\hline lackacc1 & $\begin{array}{l}\text { When running the Cherry Blossom, there are no } \\
\text { easily accessible waste receptacles along the course. }\end{array}$ \\
\hline lackacc2 & $\begin{array}{l}\text { It is just easier to throw my wrappers on the ground } \\
\text { while running than to look for a waste receptacle. }\end{array}$ \\
\hline lackacc3 & $\begin{array}{l}\text { I know if I throw my wrappers/cups on the ground } \\
\text { during the run, race workers will pick them up for me. }\end{array}$ \\
\hline
\end{tabular}

Table 1: Item Names and Item Definitions. The items had content validity and face validity as they were deemed appropriate for measuring each specific aspect as designated by several faculty and event staff. No internal consistency or construct reliability measures were attempted as the items were not designed to measure a single construct. The individual items were used in the regression analyses.

Other items included in the survey measured personal needs, values, and identity and were used solely in the cluster analysis to determine the number of groups. There were ten items representing needs (physical fitness, personal safety, financial security, true friendship, social acceptance, intimacy, family togetherness, wisdom, inner peace, and curiosity) and six items representing values (environmentalism, kindness, social justice, global peace, tolerance, and aesthetics). An additional four items represented identity (identifying as a runner, as an environmentalist, with the community, and with The Run itself). Both the needs and values items were measured on a 9-point scale, with 1 = Opposed to my Needs/Values, 2 = Not Important, 5 = Important, 8 $=$ Very Important, and $9=$ Of Supreme Importance (cf. Schwartz, 1992). The identity items were measured on a 7-point scale from $1=$ Strongly Disagree to 7 = Strongly Agree.

Demographic and geographic variables were also included in the survey. 


\section{RESULTS}

\section{Model for Total Sample}

Similar to Kim and Trail (2011), we performed a hierarchical multiple regression to test the proposed model. Correlations among the variables included in the regression are shown in Table 1 . The hierarchical regression on the whole sample supported the proposed model and the hypothesis that external constraints would explain additional variance in sustainability intentions after internal constraints were controlled for (Table 2). All the items for the two internal constraints dimensions were first entered into the regression equation as a block and explained $21.3 \%$ of the variance in sustainability behavior intentions. Then, after internal constraints had been "controlled for," all the external constraint items were entered into the regression equation as a block and explained an additional $9.8 \%$ of the variance in sustainability behavior intentions for a total of $31.3 \%$ (Figure 2).

\begin{tabular}{|c|c|c|c|c|c|c|c|c|c|c|c|c|c|c|}
\hline & $\mathbf{A}$ & $\mathbf{B}$ & $\mathbf{C}$ & $\mathbf{D}$ & $\mathbf{E}$ & $\mathbf{F}$ & $\mathbf{G}$ & $\mathbf{H}$ & $\mathbf{I}$ & $\mathbf{J}$ & $\mathbf{K}$ & $\mathbf{L}$ & $\mathbf{M}$ & $\mathbf{N}$ \\
\hline $\mathbf{A}$ & 1.000 & & & & & & & & & & & & & \\
\hline $\mathbf{B}$ & -.209 & 1.000 & & & & & & & & & & & & \\
\hline $\mathbf{C}$ & -.223 & .416 & 1.000 & & & & & & & & & & & \\
\hline $\mathbf{D}$ & -.393 & .206 & .253 & 1.000 & & & & & & & & & & \\
\hline $\mathbf{E}$ & -.250 & .402 & .459 & .155 & 1.000 & & & & & & & & & \\
\hline $\mathbf{F}$ & -.236 & .213 & .261 & .193 & .294 & 1.000 & & & & & & & & \\
\hline $\mathbf{G}$ & -.221 & .201 & .331 & .148 & .407 & .310 & 1.000 & & & & & & & \\
\hline $\mathbf{H}$ & -.198 & .341 & .328 & .092 & .462 & .249 & .319 & 1.000 & & & & & & \\
\hline $\mathbf{I}$ & -.242 & .217 & .275 & .152 & .276 & .213 & .202 & .396 & 1.000 & & & & & \\
\hline $\mathbf{J}$ & -.183 & .219 & .358 & .184 & .286 & .205 & .189 & .343 & .437 & 1.000 & & & & \\
\hline $\mathbf{K}$ & -.374 & .154 & .251 & .518 & .181 & .136 & .177 & .164 & .233 & .260 & 1.000 & & & \\
\hline $\mathbf{L}$ & -.235 & .153 & .228 & .395 & .164 & .086 & .149 & .112 & .153 & .144 & .336 & 1.000 & & \\
\hline $\mathbf{M}$ & -.452 & .111 & .171 & .449 & .139 & .092 & .167 & .127 & .122 & .142 & .558 & .273 & 1.000 & \\
\hline $\mathbf{N}$ & -.232 & .130 & .105 & .273 & .127 & .008 & .072 & .102 & .114 & .019 & .402 & .193 & .414 & 1.000 \\
\hline
\end{tabular}

Table 2: Correlations among Constraints and the DV.

Legend: $\mathrm{A}=$ intention; $\mathrm{B}=$ lacknow1; $\mathrm{C}=$ lacknow4; $\mathrm{D}=$ lacknow5; $\mathrm{E}=$ lackworth2; F=lackworth3; G= lackworth4; H=lackint1; I=lackint2; J=lackint3; K=lacktime1; $\mathrm{L}=$ lackacc1; $\mathrm{M}=$ lackacc2; N=lackacc3 


\begin{tabular}{|c|c|c|c|c|c|c|c|c|c|}
\hline \multirow{2}{*}{ Model } & \multirow{2}{*}{$\mathrm{R}$} & \multirow{2}{*}{$\begin{array}{c}\mathrm{R} \\
\text { Square }\end{array}$} & \multirow{2}{*}{$\begin{array}{c}\text { Adjusted } \\
\mathrm{R} \text { Square }\end{array}$} & $\begin{array}{c}\text { Std. Error } \\
\text { of the } \\
\text { Estimate }\end{array}$ & $\begin{array}{c}\text { R Square } \\
\text { Change }\end{array}$ & $\begin{array}{c}\mathrm{F} \\
\text { Change }\end{array}$ & $\mathrm{df1}$ & $\mathrm{df2}$ & $\begin{array}{c}\text { Sig. F } \\
\text { Change }\end{array}$ \\
\hline 1 & $.462^{\mathrm{a}}$ & .213 & .204 & .8793 & .213 & 23.642 & 6 & 524 & .000 \\
\hline 2 & $.558^{\mathrm{b}}$ & .311 & .294 & .8283 & .098 & 10.509 & 7 & 517 & .000 \\
\hline
\end{tabular}

a. Predictors: (Constant), lackworth4, lacknow5, lacknow1, lackworth3, lacknow4, lackworth2 b. Predictors: (Constant), lackworth4, lacknow5, lacknow1, lackworth3, lacknow4, lackworth2, lackacc3, lackint2, lackacc1, lackint3, lackacc2, lackint1, lacktime1

\begin{tabular}{|c|c|c|c|c|c|c|}
\hline \multicolumn{7}{|c|}{ Coefficients $^{a}$} \\
\hline & \multirow[t]{2}{*}{$\begin{array}{l}\text { Model } \\
\text { B }\end{array}$} & \multicolumn{2}{|c|}{$\begin{array}{l}\text { Unstandardized } \\
\text { Coefficients }\end{array}$} & \multirow[t]{2}{*}{$\begin{array}{l}\text { Standardized } \\
\text { Coefficients }\end{array}$} & \multirow[t]{2}{*}{$\mathrm{t}$} & \multirow[t]{2}{*}{ Sig. } \\
\hline & & Std. Error & Beta & & & \\
\hline \multirow{7}{*}{1} & (Constant) & 7.396 & .105 & & 70.366 & .000 \\
\hline & lacknow1 & -.033 & .027 & -.054 & -1.218 & .224 \\
\hline & lacknow4 & -.010 & .032 & -.014 & -.302 & .762 \\
\hline & lacknow5 & -.210 & .026 & -.330 & -8.126 & .000 \\
\hline & worth2 & -.092 & .041 & -.107 & -2.250 & .025 \\
\hline & worth3 & -.100 & .042 & -.101 & -2.384 & .017 \\
\hline & worth4 & -.056 & .030 & -.082 & -1.855 & .064 \\
\hline \multirow{14}{*}{2} & (Constant) & 7.756 & .154 & & 50.279 & .000 \\
\hline & lacknow1 & -.031 & .026 & -.051 & -1.206 & .228 \\
\hline & lacknow4 & .009 & .031 & .013 & .285 & .776 \\
\hline & lacknow5 & -.103 & .029 & -.162 & -3.500 & .001 \\
\hline & worth2 & -.066 & .040 & -.078 & -1.657 & .098 \\
\hline & worth3 & -.103 & .040 & -.103 & -2.572 & .010 \\
\hline & worth4 & -.030 & .029 & -.043 & -1.028 & .305 \\
\hline & noint1 & -.005 & .034 & -.006 & -.134 & .894 \\
\hline & noint2 & -.073 & .029 & -.109 & -2.525 & .012 \\
\hline & noint3 & .011 & .035 & .014 & .312 & .755 \\
\hline & lacktime1 & -.026 & .026 & -.049 & -.994 & .321 \\
\hline & lackacc1 & -.016 & .029 & -.022 & -.550 & .583 \\
\hline & lackacc2 & -.156 & .024 & -.300 & -6.420 & .000 \\
\hline & lackacc3 & -.004 & .024 & -.007 & -.171 & .864 \\
\hline
\end{tabular}

Table 3: Model Summary of Hierarchical Multiple Regression on the Total Sample 


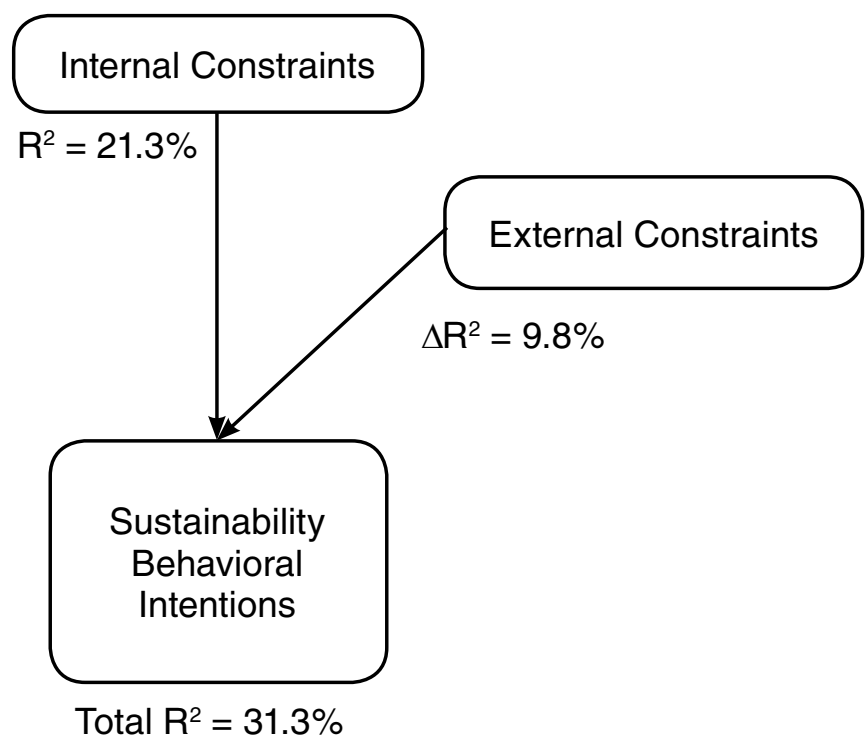

Figure 2: Impact of Internal and External Constraints on Sustainability Behavioral Intentions

Following the procedures outlined by Aldenderfer and Blashfield (1984) and supplemented by information from Sarstedt and Mooi (2014), we initially used a hierarchical cluster procedure in SPSS 22 to determine the potential number of clusters. The collinear diagnostics showed that no variables in the cluster analysis shared more than $46 \%$ of the variance (correlation table available from the authors). We determined that either 8 or 3 clusters would be most appropriate based on the dendrogram in the hierarchical analysis. We used a K-Means Cluster Analysis (squared Euclidean Distance) in SPSS 22 with the needs, values, and identity items noted above again as determining variables. Between the 3 - and 8 -cluster solutions, we chose the 8 -cluster one even though the number of iterations was the same (12) for both because the ratio of the number of cases across segments was smaller and we felt that more segments provided the potential for greater distinction. We had to eliminate 2 of the 8 clusters, however, which had only 2 and 11 cases, respectively. We thus ended up with six distinct and viable segments which existed in the sample (Figure 3).

We named Segment 1 Social Justice Visitors (SJVs) because this segment scored highly on social justice values and came primarily from out-of-town. We called Segment 2 Loyals because of their attachment to The Run and their long-term association with it. Segment 3 was labeled Unawares because they had very little knowledge about sustainability 
in general, let alone specific to The Run. Segment 4 was called Runners for Sustainability (RfS) because of their high environmentalism values and because they scored highest on having a "runner identity." We labeled Segment 5 Conventionals and also called them Inner-Focused Metros because they were primarily from the metro area and focused on their own physical fitness and financial security, with limited interest in environmentalism, global peace, or social justice. Finally, we called the last segment Local Runner Culture (LRC) because they were both highly connected to the local community and fairly highly identified as runners. There were no meaningful differences (variance $>4 \%$; see Cohen, 1988) across the segments on the demographic variables (Table 4).

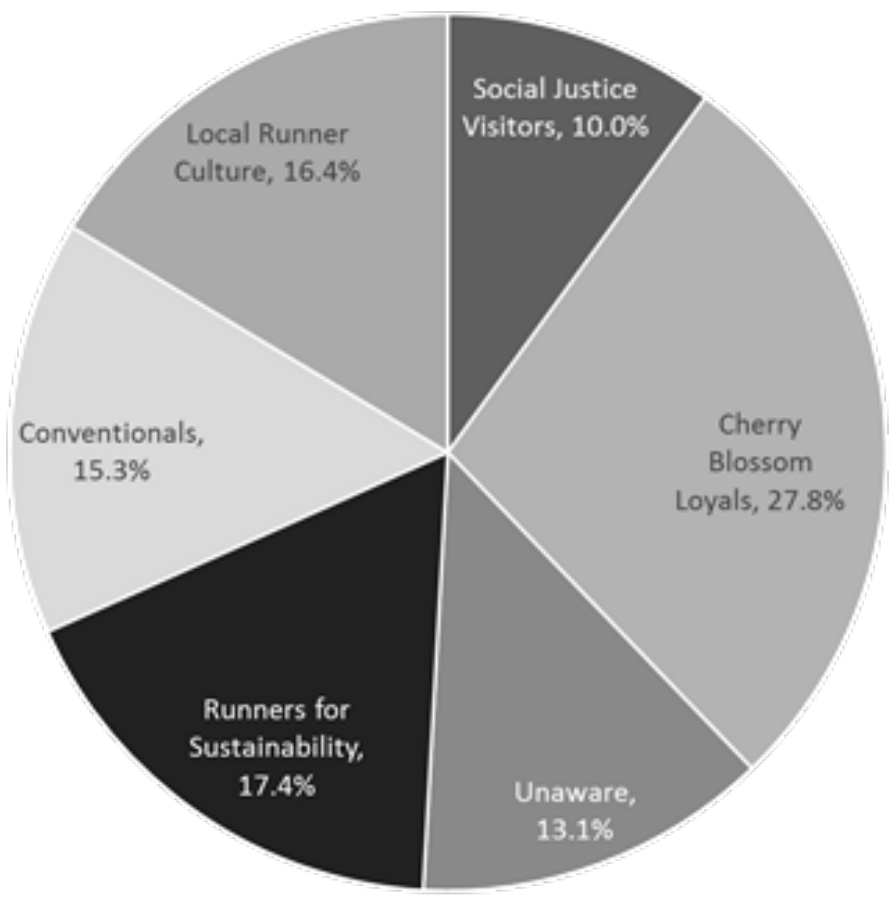

Figure 3: Runner Segments Based on Cluster Analysis.

Social Justice Visitors, 10.0\%; Cherry Blossom Loyals, 27.8\%; Unaware, 13.1\%; Runners for Sustainability, 17.4\%; Conventionals, 15.3\%; Local Runner Culture, 16.4\% 


\begin{tabular}{|c|c|c|c|c|c|c|c|c|}
\hline & $\begin{array}{l}\text { Social } \\
\text { Justice } \\
\text { Visitors }\end{array}$ & $\begin{array}{c}\text { Cherry } \\
\text { Blossom } \\
\text { Loyals }\end{array}$ & Unaware & $\begin{array}{c}\text { Runners for } \\
\text { Sustainability }\end{array}$ & Conventionals & $\begin{array}{l}\text { Local } \\
\text { Runner } \\
\text { Culture }\end{array}$ & $\begin{array}{c}\text { Total } \\
\text { Sample }\end{array}$ & $\begin{array}{l}\text { Univariate GLM } \\
\text { results }\end{array}$ \\
\hline Sex $=$ Male & $84.60 \%$ & $81.30 \%$ & $83.80 \%$ & $84.40 \%$ & $65.80 \%$ & $76.50 \%$ & $79.30 \%$ & $\begin{array}{c}F(5,512)=2.86 \\
p=.026, \eta^{2}=.025\end{array}$ \\
\hline $\begin{array}{l}\text { Education } \\
\begin{array}{c}4=\text { College } \\
\text { grad })\end{array}\end{array}$ & $\begin{array}{c}M=4.46 \\
(S D= \\
.75)\end{array}$ & $\begin{array}{l}4.54 \\
(.60)\end{array}$ & $\begin{array}{l}4.41 \\
(.58)\end{array}$ & $\begin{array}{l}4.51 \\
(.64)\end{array}$ & $\begin{array}{l}4.43 \\
(.63)\end{array}$ & $\begin{array}{l}4.51 \\
(.65)\end{array}$ & $\begin{array}{l}4.49 \\
(.63)\end{array}$ & $\begin{array}{c}F(5,512)=.54 \\
p=.748, \eta^{2}=.005\end{array}$ \\
\hline $\begin{array}{l}\text { Household } \\
\text { Income }\end{array}$ & $\begin{array}{l}\$ 117,500 \\
(\$ 33,744)\end{array}$ & $\begin{array}{l}\$ 107,500 \\
(\$ 35,199)\end{array}$ & $\begin{array}{l}\$ 86,480 \\
(\$ 31,219)\end{array}$ & $\begin{array}{l}\$ 98,140 \\
(\$ 37,071)\end{array}$ & $\begin{array}{l}\$ 107,000 \\
(\$ 33,520)\end{array}$ & $\begin{array}{l}\$ 87,420 \\
(\$ 35,180)\end{array}$ & $\begin{array}{l}\$ 98,000 \\
(\$ 34,100)\end{array}$ & $\begin{array}{c}F(5,512)=4.15 \\
p=.001, \eta^{2}=.039\end{array}$ \\
\hline $\begin{array}{l}\text { Distance } \\
\text { Traveled } \\
\text { (miles) }\end{array}$ & $\begin{array}{c}147.4 \\
(453.8)\end{array}$ & $\begin{array}{c}71.9 \\
(175.2)\end{array}$ & $\begin{array}{c}94.4 \\
(195.2)\end{array}$ & $\begin{array}{c}129.2 \\
(222.3)\end{array}$ & $\begin{array}{c}67.9 \\
(165.1)\end{array}$ & $\begin{array}{c}30.6 \\
(76.5)\end{array}$ & $\begin{array}{c}85.0 \\
(220.5)\end{array}$ & $\begin{array}{c}F(5,512)=2.86 \\
p=.015, \eta^{2}=.027\end{array}$ \\
\hline
\end{tabular}

Table 4: Segment and Total Sample Demographic Characteristics. Means are the upper value, standard deviations in parentheses.

A univariate GLM showed that the segments differed on sustainability intentions $\left[\mathrm{F}(5,517)=25.193, \mathrm{p}<.001, \mathrm{~h}^{2}=.197\right]$ (Figure 4), giving preliminary evidence that the clusters should be evaluated separately and providing criterion validity.

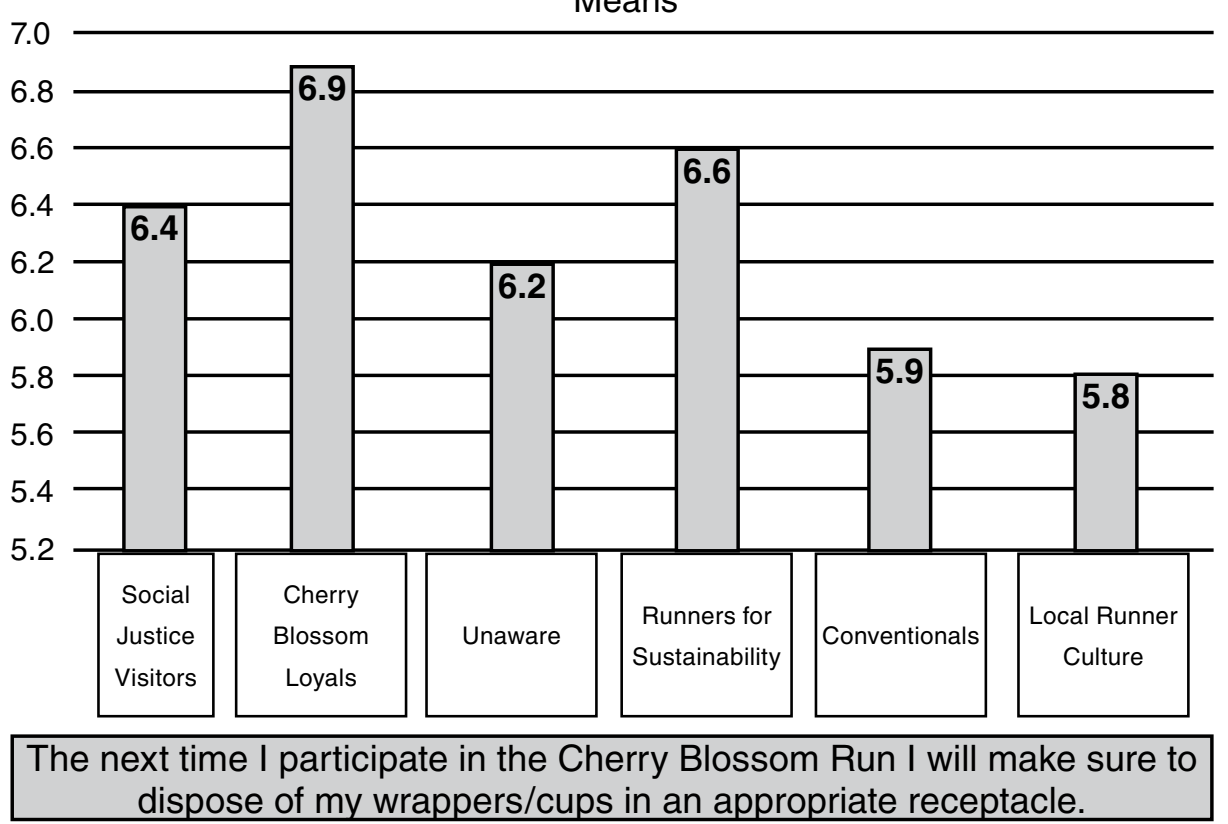

Figure 4: Means on Sustainability Intentions by Segment 
Four separate multivariate GLM analyses, moreover, showed segment differences on all four sets of constraints-the two internal constraints (Lack of Knowledge $\left[\mathrm{F}(15,1408)=31.127, \mathrm{p}<.001, \mathrm{~h}^{2}=.232\right]$ and Lack of Worth $\left.\left[\mathrm{F}(15,1408)=17.863, \mathrm{p}<.001, \mathrm{~h}^{2}=.148\right]\right)$ and the two external constraints (No Interest from Others $[\mathrm{F}(15,1408)=16.597, \mathrm{p}<.001$, $\left.\mathrm{h}^{2}=.139\right]$ and Lack of Access/Time $\left[\mathrm{F}(20,1689)=24.234, \mathrm{p}<.001, \mathrm{~h}^{2}\right.$ $=.189]$ ) (Figures 5-8). The eta squared values also showed that some clusters differed fairly substantially across the different constraint categories. Figure 5, for example, shows that the Unaware group scored significantly and meaningfully higher than the other five groups on a lack of understanding about what the term "sustainable" meant. The Loyals disagreed with that statement though, indicating that they did understand what the term meant, and they scored significantly lower (better) than the other groups on that item.

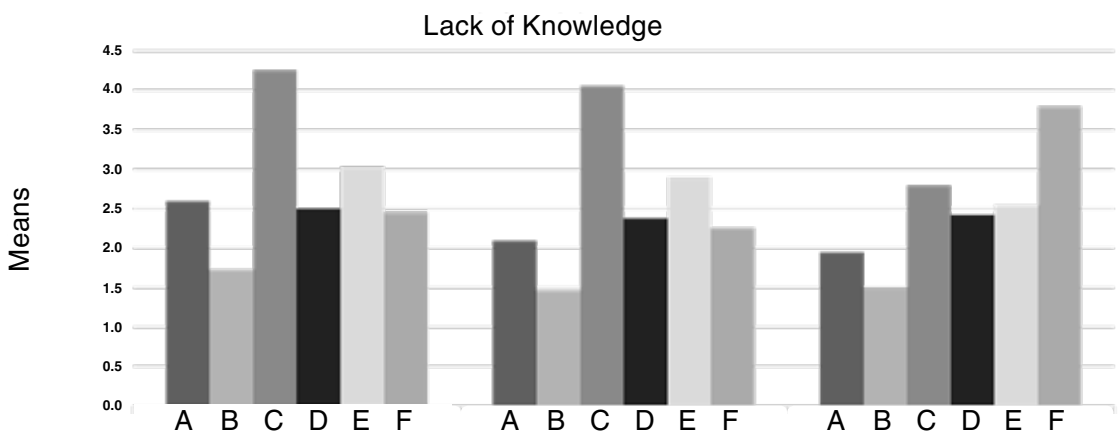

\begin{tabular}{|c|c|c|c|}
\hline & $\begin{array}{c}\text { I don't understand what the } \\
\text { term "sustainablem means } \\
\text { when applied to a race like } \\
\text { the Cherry Blossom Run. }\end{array}$ & $\begin{array}{c}\text { I don't understand what } \\
\text { the term "waste diversion" } \\
\text { means. }\end{array}$ & $\begin{array}{c}\text { I don't know how to } \\
\text { appropriately dispose of my } \\
\text { wrappers while I'm running } \\
\text { the race. }\end{array}$ \\
\hline $\begin{array}{c}\text { Social } \\
\text { Justice Visitors } \\
\text { (A) }\end{array}$ & 2.6 & 2.1 & 1.9 \\
\hline $\begin{array}{c}\text { Cherry } \\
\text { Blossom } \\
\text { Loyals (B) }\end{array}$ & 1.7 & 1.5 & 1.5 \\
\hline $\begin{array}{c}\text { Unaware (C) } \\
\text { Runners for } \\
\text { Sustainability } \\
\text { (D) }\end{array}$ & 4.3 & 4.1 & 2.8 \\
\hline $\begin{array}{c}\text { Conventionals } \\
\text { (E) }\end{array}$ & 3.0 & 2.4 & 2.4 \\
\hline $\begin{array}{c}\text { Local } \\
\text { Runner } \\
\text { Culture (F) }\end{array}$ & 2.5 & 2.9 & 2.5 \\
\hline
\end{tabular}

Figure 5: Means of Lack of Knowledge Items by Segment 


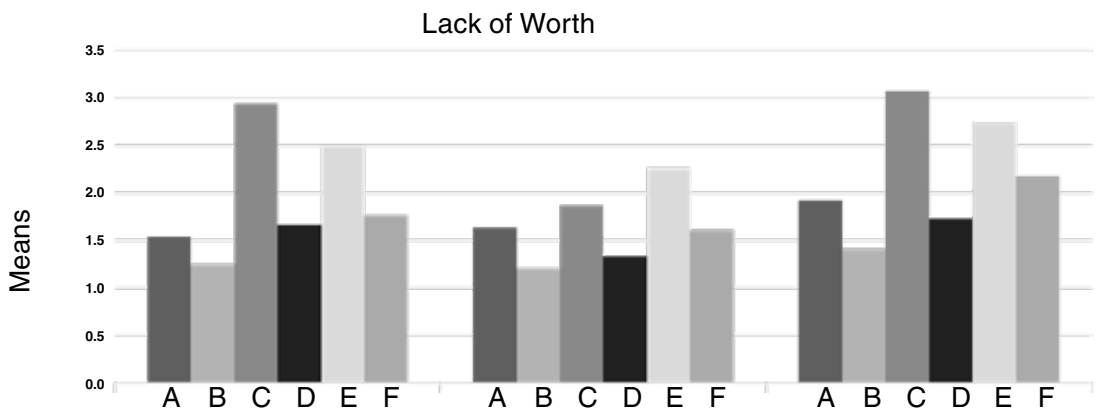

\begin{tabular}{|c|c|c|c|}
\hline & $\begin{array}{c}\text { I don't understand why } \\
\text { the Cherry Blossom Run } \\
\text { is worried about diverting } \\
\text { waste from the landfill. }\end{array}$ & $\begin{array}{c}\text { I don't think recycling is } \\
\text { worthwhile. }\end{array}$ & $\begin{array}{c}\text { Acting in an environmentally } \\
\text { friendly way won't improve } \\
\text { the environment enough to } \\
\text { make a difference. }\end{array}$ \\
\hline $\begin{array}{c}\text { Social } \\
\text { Justice Visitors } \\
\text { (A) }\end{array}$ & 1.5 & 1.6 & 1.9 \\
\hline $\begin{array}{c}\text { Cherry } \\
\text { Blossom } \\
\text { Loyals (B) }\end{array}$ & 1.3 & 1.2 & 1.4 \\
\hline $\begin{array}{c}\text { Unaware (C) } \\
\text { Runners for } \\
\text { Sustainability } \\
\text { (D) }\end{array}$ & 2.9 & 1.9 & 3.1 \\
\hline $\begin{array}{c}\text { Conventionals } \\
\text { (E) }\end{array}$ & 1.7 & 1.3 & 1.7 \\
\hline $\begin{array}{c}\text { Local } \\
\text { Runner } \\
\text { Culture (F) }\end{array}$ & 2.5 & 2.3 & 2.7 \\
\hline
\end{tabular}

Figure 6: Means of Lack of Worth Items by Segment 


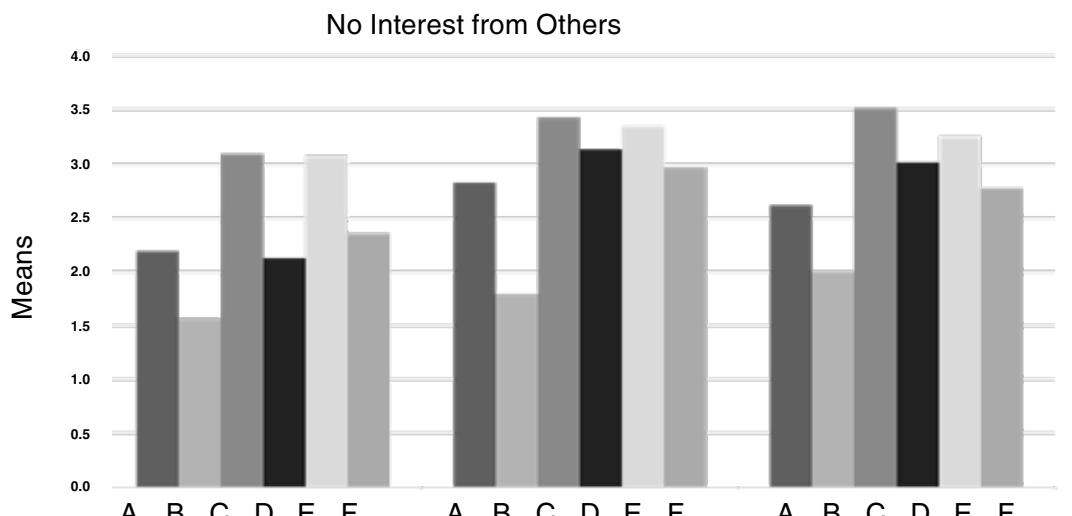
A B C D E F
A $B$ C $D$ E $F$
A B C D E F

\begin{tabular}{|c|c|c|c|}
\hline & $\begin{array}{c}\text { My family is not interested } \\
\text { in acting sustainably. }\end{array}$ & $\begin{array}{c}\text { My significant other is } \\
\text { not interested in acting } \\
\text { sustainably. }\end{array}$ & $\begin{array}{c}\text { My friends are not interested } \\
\text { in acting sustainably. }\end{array}$ \\
\hline $\begin{array}{c}\text { Social } \\
\text { Justice Visitors } \\
\text { (A) }\end{array}$ & 2.2 & 2.8 & 2.6 \\
\hline $\begin{array}{c}\text { Cherry } \\
\text { Blossom } \\
\text { Loyals (B) }\end{array}$ & 1.6 & 1.8 & 2.0 \\
\hline $\begin{array}{c}\text { Unaware (C) } \\
\text { Runners for } \\
\text { Sustainability } \\
\text { (D) }\end{array}$ & 3.1 & 3.4 & 3.5 \\
\hline $\begin{array}{c}\text { Conventionals } \\
\text { (E) }\end{array}$ & 2.1 & 3.1 & 3.3 \\
\hline $\begin{array}{c}\text { Local } \\
\text { Runner } \\
\text { Culture (F) }\end{array}$ & 3.1 & 3.3 & 2.8 \\
\hline
\end{tabular}

Figure 7: Means of No Interest from Others Items by Segment 


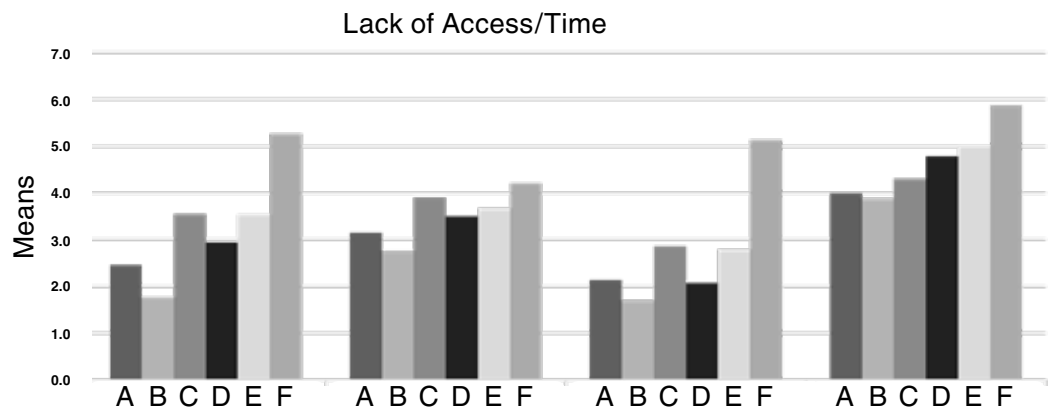

\begin{tabular}{|c|c|c|c|c|}
\hline & $\begin{array}{c}\text { I don't have time } \\
\text { to find a waste } \\
\text { receptacle while } \\
\text { I'm running the } \\
\text { race. }\end{array}$ & $\begin{array}{c}\text { When running the } \\
\text { Cherry Blossom, } \\
\text { there are no easily } \\
\text { accessible waste } \\
\text { receptacles along } \\
\text { the course. }\end{array}$ & $\begin{array}{c}\text { It is just easier to } \\
\text { throw my wrappers } \\
\text { on the ground while } \\
\text { running than to } \\
\text { look for a waste } \\
\text { receptacle. }\end{array}$ & $\begin{array}{c}\text { I know if I throw } \\
\text { my wrappers/cups } \\
\text { on the ground } \\
\text { during the run, race } \\
\text { workers will pick } \\
\text { them up for me. }\end{array}$ \\
\hline $\begin{array}{c}\text { Social } \\
\text { Justice Visitors } \\
\text { (A) }\end{array}$ & 2.5 & 3.2 & 2.1 & 4.0 \\
\hline $\begin{array}{c}\text { Cherry Blossom } \\
\text { Loyals (B) }\end{array}$ & 1.8 & 2.8 & 1.7 & 3.9 \\
\hline $\begin{array}{c}\text { Unaware (C) } \\
\text { Runners for } \\
\text { Sustainability } \\
\text { (D) }\end{array}$ & 3.5 & 3.9 & 2.9 & 4.3 \\
\hline $\begin{array}{c}\text { Conventionals } \\
\text { (E) }\end{array}$ & 3.5 & 3.5 & 2.1 & 4.8 \\
\hline $\begin{array}{c}\text { Local } \\
\text { Runner Culture } \\
\text { (F) }\end{array}$ & 5.3 & 4.7 & 2.8 & 5.0 \\
\hline
\end{tabular}

Figure 8: Means of Lack of Access/Time Items by Segment

\section{Model Testing and Fit}

Stepwise hierarchical regression analyses on each segment showed differential impacts of internal and external constraints on sustainability intentions. Similar to the regression for the entire data set, the internal constraint items were all entered in the first block for each segment followed by all of the external constraints entered in the second block.

\section{Relationships Between IVs and DVs}

For Social Justice Visitors, internal constraints (specifically Lack of Knowledge) explained $8.5 \%$ of the variance in intentions to dispose of waste properly while external constraints (Lack of Access) explained an 
additional $17.3 \%$ for a total of $25.8 \%$ of the variance. For Loyals, internal constraints (Lack of Knowledge and Lack of Worth) explained 10.3\% and external constraints (Lack of Time) an additional 2.6\% for a total of $12.9 \%$ of the variance in intentions to dispose of waste properly. For the Unaware segment, Lack of Worth (internal) explained 23.2\% and Lack of Time (external) an additional $7.1 \%$ for a total of $30.3 \%$ of the variance. For the Runners for Sustainability segment, Lack of worth explained $10.0 \%$ and Lack of Knowledge an additional $6.6 \%$ (both internal constraints) for a total of $16.6 \%$; external constraints were not significantly related to intentions for this segment. For the Conventionals segment, Lack of Knowledge explained 18.1\% and Lack of Worth an additional 4.1\% (both internal constraints) while Lack of Access explained an additional 10.9\% for a total of $33.1 \%$. Finally, for the Local Runner Culture segment, the internal constraint of Lack of Knowledge explained 5.7\% and Lack of Access explained an additional $5.7 \%$ for a total of $11.4 \%$ of the variance in intentions to dispose of waste properly. The beta weights and total variance are shown in Figure 9.

Social Justice Visitors
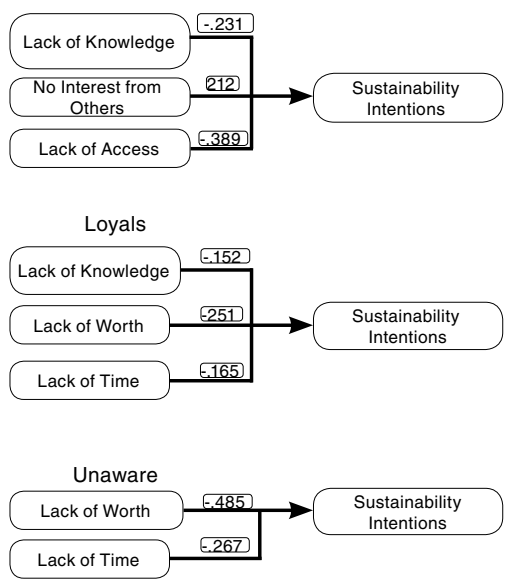

Runners for Sustainability

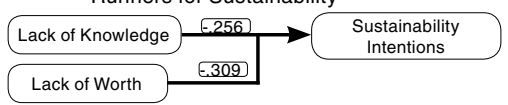

Conventionals
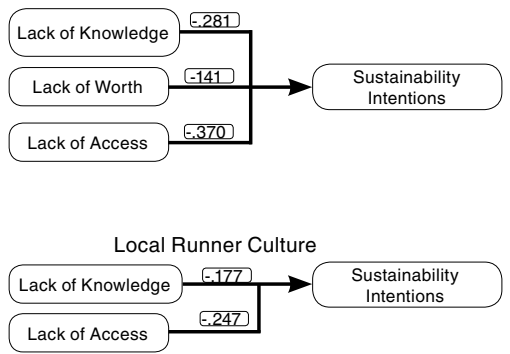

Figure 9: Beta Values for Path Coefficients for Significant Predictors Only on Sustainability Intentions by Segment

\section{DISCUSSION}

The focus of the study was to use constraint theory (Crawford \& Godbey, 1987; Crawford et al., 1991; Kim \& Trail, 2010, 2011) to investigate the impact of internal and external constraints on sustainability behavior intentions of participants in a 10M run. Market segmentation has typically been used to examine whether different 
groups of people have different sustainability attitudes or behave in different ways (Belz \& Peattie, 2012). When distinct and viable segments are determined, organizations can create different communication or sustainability campaigns to address each segment more effectively and efficiently instead of wasting resources directing communications to an audience that has no interest in the message. We specifically proposed that lack of knowledge about sustainability and perceiving that acting sustainably has no value or lacks worth (internal constraints) as well as lack of interest from others concerning sustainability and lack of time or access relative to sustainability actions (external constraints) would negatively impact the sustainability intentions of participants in The Run when it came to waste diversion. We also proposed that the model would hold across segments although with the impact of the constraints on the intentions varying by segment.

\section{Overview of the Significant Findings}

The model fit the data well when tested on the entire sample. Internal constraints such as lack of knowledge and perceived lack of worth do predict variance in intentions to act sustainably, specifically in this instance of proper waste disposal either by recycling, composting, or putting trash in the correct receptacle. Once internal constraints were controlled for, the external constraints of lack of interest by others to act sustainably and lack of time and access explained additional variance in sustainability intentions.

We suspected, however, that multiple segments of participants would exist based on Belz and Peattie's (2012) suppositions and that they would differ not only in beliefs about constraints and sustainability intentions (which they did) but also in the impact of internal and external constraints on intentions. That is, we hypothesized that different constraints would impact each segment differently. This was borne out as each segment had a different set of constraints that negatively impacted intentions, and the amount of variance the constraints explained in sustainability intention went from as low as $11.4 \%$ in the Local Runner Culture segment to as high as $33.1 \%$ in the Conventionals segment.

For the Social Justice visitors, the internal constraint of lack of knowledge did not have a substantial impact on intentions to dispose of waste properly; perceived lack of worth was also not significant at all. This indicates, not surprisingly, that internal constraints for this segment could easily be overcome if necessary. The external constraint of lack of access, however, was a substantial negative predictor of intentions, showing that organizers of The Run had not sufficiently educated this 
segment about how and where to dispose of their waste during the race. This differed from the Loyals quite a bit.

For the Loyals, lack of knowledge was a slight constraint. Perceived lack of worth had a larger negative impact on intentions, but this was still relatively small. This indicated that the Loyals generally saw the value of diverting waste from the landfill (100\% agreed with this sentiment) and were generally knowledgeable about sustainability and what The Run was trying to accomplish. They were supportive of The Run's agenda, having been associated with it for long enough and sufficiently educated about the event's endeavors to be sustainable. However, the more the Loyals felt that they did not have sufficient time to find a waste receptacle when running the race, the less likely they were to dispose of waste correctly. Luckily only $4.9 \%$ of this segment indicated that they would not do so.

While the Unaware segment indicated that their lack of knowledge was a constraint, it was not the primary predictor of their intentions. More importantly, this segment unfortunately did not see the value of acting sustainably (lack of worth) - the more they did not think recycling was worthwhile, the more likely they were to just throw their waste on the ground and not dispose of it properly. Moreover, even if this internal constraint could be ameliorated through educational communications, this segment did not think they would have the time to find a waste receptacle during the race (external constraint). The Run will have to do quite a bit of work to get this group to dispose of their waste properly during the event.

Less than $2 \%$ of the Runners for Sustainability segment felt that recycling was not worthwhile, but as this internal constraint increased, they were more likely to throw their waste on the ground as they raced. Partially this was due to a lack of knowledge about appropriately disposing of waste (e.g., wrappers, etc.) during the race, as $11 \%$ of this segment indicated they did not know how to do so. This lack of sufficient education for this segment was The Run's fault to some extent, especially since a majority of this segment had never run this race before. Appropriate educational communications would probably alleviate these internal constraints fairly easily as these runners already want to act sustainably and intend to do so. This segment had no influence from external constraints, indicating that they would take the time to access the waste receptacles and dispose of their waste appropriately during The Run.

The Conventionals lacked knowledge about sustainability in general, and specifically about how to dispose of waste appropriately, second only to the Unaware segment. This, moreover, was a substantial constraint 
for them to act responsibly during the race. They also did not see the value of The Run trying to divert waste from the landfill, although this impacted their actions less than their lack of knowledge did. It seems that The Run would have difficulty convincing this group to change their attitudes and educating them to act more sustainably given that they are not interested in acting environmentally consciously in the first place. Indeed, even if such internal constraints could be overcome, these Conventionals indicated that they would find it easier to just to throw their wrappers on the ground than try to find a waste receptacle. Educating them in an attempt to change their behavior would probably be an arduous process.

The final segment, Local Runner Culture, was not constrained very much at all; in fact, they were the least impacted by constraints out of all the segments. Their largest internal constraint, a lack of understanding what the term "sustainable" meant, negatively impacted their disposal behavior during the race only to a small degree. Such a constraint can easily be reduced or eliminated by communicating with this segment better and educating them about the term. Only one external constraint had a significantly negative impact-their belief that there were no easily accessible waste receptacles along the course. This was an accurate assessment to some extent as The Run had only recently improved accessibility to waste receptacles along the course and had not yet implemented a communication campaign to educate the Runners about the ease of disposing of their waste. Nevertheless, this was a very small constraint for this segment and could be easily ameliorated through education because this group did want to dispose of their waste properly.

\section{Implications for the Study}

Internal constraints need to be dealt with first through educating the participants not only on how to act more sustainably but also on the importance of doing so not only for the event but for other participants, spectators, and the local community. Ameliorating internal constraints, however, is typically more challenging than dealing with external constraints. Making people aware of sustainability issues is not overly difficult but changing belief systems certainly is.

Fixing external constraints, therefore, is usually less difficult, and is often something under the organization's control. For example, The Run needed to make the waste receptacles much easier to access during the race itself as well as increase their number and frequency along the course. Organizers then needed to communicate better where the receptacles were located, both before (through more extensive 
communications) and during (with better signage along the course indicating that waste receptacles were coming up) the race.

The key for organizations is to communicate and educate better than they typically do. Positively reinforcing sustainable behaviors while trying to decrease bad ones should also help. Organizations need to understand, however, that they have different segments, that these segments have different belief systems and levels of knowledge, and that these will respond differently to various communications and education attempts. Organizations need to understand their different segments and appropriately communicate with each.

\section{Limitations}

One obvious limitation of this study was that it was focused solely on one event at one time and so may not be as generalizable as desired. Similar to previous research, however, the model was supported in general and in each of the segments studied. Taken as a whole, therefore, this evidence ameliorates the generalizability concern to some extent. Second, given that ours is a cross-sectional study that occurred before the event, we were unable to collect actual behaviors of the runners during the race itself. We even wanted to do a follow up study after the race but the organization was not inclined. Third, while there are additional constraints that might have been examined, we focused on the ones that we felt (based on previous research) were those most likely to explain behavioral intentions.

\section{Recommendations}

Practitioners are encouraged to evaluate the constraints customers (e.g., participants) may encounter that may inhibit them from engaging in desired behaviors (e.g., recycling, composting, etc.). While the internal and external constraint dimensions (not necessarily the specific items) used in this study are applicable to other contexts in and outside of sport, researchers and practitioners alike should determine the specific constraint items that are relevant to their context and that may inhibit desired behavioral outcomes. As noted above, moreover, organizations need to deal with internal constraints first. When dealing with waste disposal issues, for example, they need to enhance education on what recycling and composting mean in general. They need to improve education communications on the benefits of recycling and composting to increase their perceived worth/value. 
However, even if internal constraints are controlled, external constraints may still prevent people from performing sustainable behaviors. Organizations, for instance, still need to enhance communications on the processes of recycling/composting that are specific to the particular event so that participants understand how to dispose of their waste properly. They also need to check whether family and friends' beliefs about sustainability impact the actions of the participant (although that was not relevant in this particular sample). If so, the organization needs to educate not only the participants but friends and family as well concerning acting sustainably.

That being said, these communications probably need to vary by segment because each segment is impacted by various internal and external constraints in different ways. Each organization, therefore, needs to do their own research to determine what segments exist and what specific constraints are relevant to each. Once those are determined, segment-specific communications can be created for each.

\section{CONCLUSION}

We found support for constraint theory and the hierarchical constraint model which shows that internal constraints need to be addressed first before external constraints become relevant. Both, however, typically have negative impacts on sustainability behavior and need to be ameliorated if not eliminated. We also showed that it is very important for organizations to realize that they probably have multiple segments of participants, customers, or clients and that they need to interact and communicate with each segment differently. Finally, we suggested various ways of addressing both the internal and external constraints, both those specific to The Run and in general.

\section{REFERENCES}

Ajzen, I. 1991. The theory of planned behavior. Organizational Behavior and Human Decision Processes, 50(2): 179-211.

Aldenderfer, M. S., \& Blashfield, R. K. 1984. Cluster analysis. Newbury Park, CA: Sage Publishing.

Ashforth, B. E., \& Gibbs, B. W. 1990. The double-edge of organizational legitimation.

Organization Science, 1(2): 177-194.

Babiak, K., \& Trendafilova, S. 2011. CSR and environmental responsibility: Motives and pressures to adopt green management practices. Corporate Social Responsibility and Environmental Management, 18(1): 11-24. DOI: 10.1002/csr.229. 
Belz, F-M., \& Peattie, K. 2012. Sustainability marketing (2nd ed.). West Sussex, UK: John Wiley \& Sons, Ltd.

Casper, J., Pfahl, M., \& McCullough, B. P. 2014. Engaging fans in intercollegiate sustainability efforts: Understanding the environmental perspectives and actions of sport fans. Journal of Issues in Intercollegiate Athletics, 7: 65-91.

Casper, J., Pfahl, M., \& McCullough, B. P. 2017. Is "going green" worth it? Assessing fan engagement and perceptions of athletic department environmental efforts. Journal of Applied Sport Management, 9(1): 106-134. DOI: 10.18666/JASM2017-V9-I1-7690.

Cohen, J. 1988. Statistical power analysis for the behavioral sciences (2nd ed.). Hillsdale, NJ: Lawrence Erlbaum Associates.

Collins, A., Jones, C., \& Munday, M. 2009. Assessing the environmental impacts of mega sporting events: Two options? Tourism Management, 30(6): 828-837.

Crawford, D. W., \& Godbey, G. 1987. Reconceptualising barriers to family leisure. Leisure Sciences, 9(2): 119-127.

Crawford, D. W., Jackson, E. L., \& Godbey, G. 1991. A hierarchical model of leisure constraints. Leisure Sciences, 13(4): 309-320.

Ferrell, O. C., \& Hartline, M. D. 2005. Marketing strategy (3rd ed.). Mason, OH: South-Western.

Fink, J. S., Trail, G. T., \& Anderson, D. F. 2002. An examination of team identification: Which motives are most salient to its existence? International Sports Journal, 6(2): 195-207.

Ihlen, Ø. 2009. Business and climate change: The climate response of the world's 30 largest corporations. Environmental Communication, 3(2): 244-262.

Iso-Ahola, S. 1981. Leisure counseling at the crossroads. The Counseling Psychologist, 9(3): 71-74.

Juvan, E., \& Dolnicar, S. 2014. The attitude-behaviour gap in sustainable tourism. Annals of Tourism Research, 48: 76-95.

Kaplowitz, M. D., Yeboah, F. K., Thorp, L., \& Wilson, A. M. 2009. Garnering input for recycling communication strategies at a Big Ten University. Resources, Conservation and Recycling, 53(11): 612-623.

Kates, R. W., Clark, W. C., Corell, R., Hall, J. M., Jaeger, C. C., Lowe, I., McCarthy, J. J., Schellnhuber, H. J., Bolin, B., Dickson, N. M., Faucheux, S., Gallopin, G. C., Grübler, A., Huntley, B., Jäger, J., Jodha, N. S., Kasperson, R. E., Mabogunje, A., Matson, P., Mooney, H., Moore III, B., O’Riordan, T., \& Svedin, U. 2001. Sustainability science. Science, 292(5517): 641-642.

Kay, T., \& Jackson, G. 1991. Leisure despite constraint: The impact of leisure constraints on leisure participation. Journal of Leisure Research, 23(4): 301-313.

Kellison, T. B., \& McCullough, B. P. 2016. A forecast for the mainstreaming of environmental sustainability. Sport \& Entertainment Review, 2(1): 11-18.

Kim, Y. K., \& Trail, G. T. 2010. Constraints and motivators: A new model to explain sport consumer behavior. Journal of Sport Management, 24(2): 190-210.

Kim, Y. K., \& Trail, G. T. 2011. Factors influencing spectator sports consumption: NCAA women's college basketball. International Journal of Sports Marketing and Sponsorship, 13(1): 55-77. 
Lepisto, L. R., \& Hannaford, W. J. 1980. Purchase constraint analysis: An alternative perspective for marketers. Journal of the Academy of Marketing Science, 8(1): $12-25$.

Martin, M., Williams, I. D., \& Clark, M. 2006. Social, cultural and structural influences on household waste recycling: A case study. Resources, Conservation and Recycling, 48(4): 357-395.

Martin, N. T., Ross, S. R., \& Irwin, R. L. 2015. Utilizing community-based social marketing in a recycling intervention with tailgaters. Journal of Intercollegiate Sport, 8(1): 57-81.

McCullough, B. P. 2013. Understanding sport spectator recycling: A qualitative approach. International Journal of Sport Management and Marketing, 14(1-4): 146-168.

McCullough, B. P., \& Cunningham, G. B. 2011. Recycling intentions among youth baseball spectators. International Journal of Sport Management and Marketing, 10(1/2): 104-120. DOI: 10.1504/IJSMM.2011.043618.

McCullough, B. P., Pfahl, M. E., \& Nguyen, S. N. 2016. The green waves of environmental sustainability in sport. Sport in Society, 19(7): 1040-1065.

McDonald, M. A., Milne, G. R., \& Hong, J. 2002. Motivational factors for evaluating sport spectator and participant markets. Sport Marketing Quarterly, 11(2): $100-113$.

Morsing, M., \& Schultz, M. 2006. Corporate social responsibility communication: Stakeholder information, response and involvement strategies. Business Ethics: A European Review, 15(4): 323-338.

O'Brien, D., \& Chalip, L. 2007. Sport events and strategic leveraging: Pushing towards the triple bottom line. In A. Woodside \& D. Martin (Eds.), Tourism management: Analysis, behaviour and strategy: 318-338. Cambridge, MA: CABI Publishing.

Pritchard, M. P., Funk, D. C., \& Alexandris, K. 2009. Barriers to repeat patronage: The impact of spectator constraints. European Journal of Marketing, 43(1/2): 169-187.

Sarstedt, M., \& Mooi, E. 2014. A concise guide to market research: The process, data, and methods using IBS SPSS Statistics (2nd ed.). New York: Springer-Verlag. DOI: $10.1007 / 978-3-642-53965-7$.

Sartore-Baldwin, M. L., \& McCullough, B. P. 2018. Equity-based sustainability and ecocentric management: Creating more ecologically just sport organization practices. Sport Management Review, 21(4): 391-402. DOI: 10.1016/j.smr.2017.08.009.

Sartore-Baldwin, M. L., McCullough, B. P., \& Quatman-Yates, C. 2017. Shared responsibility and issues of injustice and harm within sport. Quest, 69(3): 366-383.

Schwartz, S. H. 1992. Universals in the content and structure of values: Theoretical advances and empirical tests in 20 countries. In M. Zanna (Ed.), Advances in experimental social psychology, vol. 25: 1-65. Orlando, FL: Academic Press.

Scott, D. 1991. The problematic nature of participation in contract bridge: A qualitative study of group-related constraints. Leisure Sciences, 13(4): 321-336. 
Shaw, S. M., Bonen, A., \& McCabe, J. F. 1991. Do more constraints mean less leisure? Examining the relationship between constraints and participation. Journal of Leisure Research, 23(4): 286-300.

Stern, P., Dietz, T., Kalof, L., \& Guagnano, G. 1995. Values, beliefs, and proenvironmental action: Attitude formation toward emergent attitude objects. Journal of Applied Social Psychology, 25(18): 1611-1636.

Sutton, W. A., McDonald, M. A., Milne, G. R., \& Cimperman, J. 1997. Creating and fostering fan identification in professional sports. Sport Marketing Quarterly, 6: $15-22$.

Taylor, S., \& Todd, P. 1995. An integrated model of waste management behavior: A test of household recycling and composting intentions. Environment and Behavior, 27(5): 603-630.

Trail, G. T., \& James, J. D. 2015. Sport consumer behavior (2nd ed.). Seattle, WA: Sport Consumer Research Consultants LLC.

Trendafilova, S., McCullough, B., Pfahl, M., Nguyen, S. N., Casper, J., \& Picariello, M. 2014. Environmental sustainability in sport: Current state and future trends. Global Journal on Advances in Pure \& Applied Sciences, 3: 9-14.

United Nations. 2010. United Nations environmental programme: Sport and environment. Available at http://www.unep.org/sport_env/.

United Nations. 2016. Paris agreement. Paris: United Nations.

United Nations. 2017. Sports representatives and the UN pitch for climate action. Available at https://cop23.unfccc.int/news/sports-representatives-and-the-unpitch-for-climate-action.

Wedel, M., \& Kamakura, W. A. 2000. Market segmentation: Conceptual and methodological foundations. Norwell, MA: Kluwer Academic Publishers.

Galen Trail is a Professor of Sport Business Leadership in the Marketing Department at the Albers School of Business \& Economics, Seattle University. He earned his Ph.D. at The Ohio State University and his current research interests include consumer values and sustainability campaign assessment.

Brian P. McCullough is an Associate Professor of Sport Business Leadership in the Management Department at the Albers School of Business \& Economics, Seattle University. He earned his Ph.D. at Texas A\&M University and his current research interests include the decision-making processes for integrating environmental sustainability into the business of sport and assessing the sustainable behaviors of sports fans/participants. 